\title{
Challenges and Opportunities of Implementing E-Learning in Teaching English at Tertiary Level from Teachers' Perspective
}

\author{
Ngoan Pham Thi ${ }^{1, *}$ Duc Nguyen Minh $^{2}$ \\ ${ }^{I}$ Faculty of Foreign Languages, Nguyen Tat Thanh University, HCMC \\ ${ }^{2}$ Faculty of Foreign Languages, Nguyen Tat Thanh University, HCMC \\ *Corresponding author. Email: ptngoan@ntt.edu.vn
}

\begin{abstract}
Due to the Covid-19 pandemic, tremendous Vietnamese lecturers are assumed to have conducted virtual teaching in response to keep track of learning progress. This type of teaching seemingly brings several benefits to students and teachers. However, not all English instructors show their proficiency in applying e-Learning platforms. The present study was conducted with an aim to investigate the obstacles and chances given to both English lecturers when teaching online. A sample of 69 English lecturers from diverse universities in Ho Chi Minh City was selected with convenience and random sampling. The research instruments included online questionnaires and semi-structured interviews. After administering questionnaires to gain responses and screening data, six lecturers were interviewed to have further ideas explored. Having analysed the piloted data, the preliminary findings have revealed that the virtual platforms are beneficial to teachers in terms of interaction, flexibility, and lesson delivery. They also indicated some problems such as application interruptions and students' lack of enthusiasm. The study will help English lecturers and practitioners raise awareness of conducting e-Learning and offer them some solutions to maximize this type of teaching
\end{abstract}

Keywords: online learning, distant learning, Covid-19 pandemic, advantages, and disadvantages.

\section{INTRODUCTION}

E-learning has emerged in the form of distance courses with the purposes of equipping students with certain knowledge or skills for ages. With the rapid technological development in the late $20^{\text {th }}$ century, it is supposed that e-Learning has become an indispensable part in necessitating students' learning globally and domestically. Students from different parts of the world can get access to the availability of learning materials thanks to Internet or Intranet connection. According to [1], e-Learning has been employed by many worldwide universities. It is considered a replacement for face-to-face learning in certain circumstances. This type of learning has been progressing insignificance in alignment with technological enhancement.

In the Vietnamese context, e-Learning has been identified as a key element in educational growth since the 2000s, and lots of policies have been established to boost e-Learning development, including school's information technology infrastructure and ICT applications upgrading [2]. Notably, in the light of the Covid-19 pandemic occurrence, social distancing rules have promoted virtual learning and working, which has tremendous impacts on instructors [3]. To ensure students' health and keep track of learning progress, numerous universities have applied online teaching in different subjects, including English. With a sudden shift, English instructors are assumed to encounter certain obstacles in using e-Learning platforms and applications effectively. Despite these challenges, eLearning is beneficial in terms of flexibility, costeffectiveness, learners' self-pacing, and interaction [23]. There have been both foreign and Vietnamese scholars sparking their interest in the benefits and challenges of employing e-Learning in teaching English at tertiary institutions. [23]; [4], and [6], [7] and [17] found that e-Learning enables teachers and 
students to get access to different types of material, learn flexibly, promote learning autonomy and peer interaction. By contrast, virtual learning hinders teachers and learners from having actual interaction, ineffective interpersonal communication, assessment of students' capabilities, time consumption, and necessary computing literacy. [8] asserted that research and technological innovations are eLearning's plus point while digital competence, assessment \& supervision, heavy workload, and compatibility are the unexpected drawbacks.

The present study was conducted with an aim to investigate the teachers' perceptions related to the challenges and opportunities of using e-Learning platforms in teaching English at the university level.

\subsection{Research questions}

To accomplish this objective, two research questions were addressed:

- To what extent are e-Learning platforms beneficial in teaching English for university students?

- What are the challenges of implementing eLearning in teaching English for university students?

\section{LITERATURE REVIEW}

\subsection{What is E-learning}

E-learning is said to occur whenever a person reveals a certain piece of knowledge from an electronic resource [26]. In other words, it is any course that involves an electronic approach to achieve its goals. Thanks to its benefits, E-learning provides teachers and educators with futuristic methods to deliver information to their students and thus improve their teaching practice [29]. Since its appearance, E-learning has made improvements to several drawbacks of traditional classroom teaching, which requires students to be present at a fixed place in a scheduled period. In the best scenario, E-learning allows teachers and learners to improve their pedagogical path through the help of the Internet. From the teachers' side, content delivery is now more effective while students have more opportunities to explore the world of knowledge.

\subsection{Types of E-learning}

\subsubsection{Synchronous and Asynchronous}

In its broadest sense, E-learning happens in both synchronous and asynchronous styles. In synchronous mode, the learning experience involves direct interaction with teachers or tutors, either oneon-one or one-to-many. The process of learning requires students to be present in a virtual classroom via the Internet at a specific time pre-selected. This type of online learning provides learners with the ability to interact, discuss and improve their knowledge. They are also able to receive instant feedback from their tutor when necessary. However, with the requirement to gather at the same time, synchronous online learning eliminates one important aspect of E-learning which is the ability to decide when and where to learn. Consequently, asynchronous learning is an alternative approach that fits well with the definition of E-learning when teachers and learners are not required to be at the same time. It is said to be more convenient for learners due to the capability to access the course delivery either at work or at home [24].

\subsubsection{Other classifications}

When discussing the design of E-learning [30] defined several possible types of E-learning courses learners may encounter on the way to gaining their knowledge. These types include

(i) standalone courses: These are courses that are designed so that learners are able to learn individually in their own paces with little or even no interactions with other class members or instructors;

(ii) learning games and simulations: In this type of learning, learners are taken through simulations that help the student discover new awareness through exploration;

(iii) mobile learning: This way of learning provides a solution for students to learn while they are moving from one place to another. Through the aid of smart devices such as mobile phones or tablets, they are able to join traditional classrooms or participate in standalone courses.

(iv) social learning: In this approach, learners gain their knowledge by interacting with experts and other group members of the community. Learning often takes place through social network environment;

(v) virtual-classroom course: This way of teaching imitates the form of a traditional classroom in which there are assignments, classroom presentations, homework, and classroom participation. However, the difference is that all class members are connected by online meeting tools through the Internet. 


\subsection{The Importance of E-learning}

Due to the impact of the Covid-19 crisis, schools in every corner of the world are closed in order to stop the spread of Coronavirus. The fact that the lockdown scenario has not come to an end makes educators switch schools and universities to online pedagogical mode. This way of learning is said to bring various benefits to learners thanks to its unique features.

\subsubsection{Flexible}

With the help of the Internet, students have the capability to decide where or when to study. Learning is easily accessible for learners when they are traveling on a train, waiting for a bus, or at home after a working day. Through the e-Learning approach, students are able to accustom their scheduled learning process according to their personal needs ([5] and [19]).

Besides, it is important for educators to maintain pedagogical standards at a similar level to traditional teaching. With the help of various sources available, it is much easier for teachers to vary their teaching methods to fit different learning styles of learners. They are able to transfer traditional activities into a wide range of activities using online tools to improve students' motivation and thus enhance teaching quality.

\subsubsection{Accessible}

When an online course is delivered online, its content will be accessible from every corner of the world. Consequently, students from different parts of the world have more chances to access and learn new knowledge [25]. This benefits students from rural areas or developing countries who find it challenging to study on-site. Thanks to online learning, it is much easier for them to enrich their knowledge from a far distance, which helps assure educational equality between countries [28].

\subsubsection{Cost-effective}

E-learning is said to be more effective in terms of cost due to a number of reasons. Firstly, there is no need for students to travel back and forth from their residential location to their educational area. Secondly, institutions can save more money as it is unnecessary to build huge buildings to house students when they are allowed to access the teaching and learning system from a far distance. Moreover, if designed effectively for online mode, teaching materials are able to be used as many times as possible with little or even no extra cost. These aspects contribute to the cost reduction of the teaching and learning process.

\subsubsection{Self-paced}

E-learning enables students' opportunities to learn at their own pace. They do not need to worry about the length of time to finish a certain assignment or complete an activity at a specific moment. This is most suitable for people who are working on several tasks synchronously. They are able to choose the right time to start a learning activity according to their own schedules. This helps increase their satisfaction while learning.

In the Vietnamese context, most educational institutions are well-adapted to the new normal conditions of the pandemic through teaching and learning online with appropriate policies provided [34]. Consequently, this study does not focus on the cost of implementing an E-learning approach as it is already an important factor that most universities are aiming at.

\subsection{Problems with E-learning}

\subsubsection{Technological Requirement}

For an online course to happen, a combination of internet connection and smart devices such as smartphones or computers is mandatory. It is worth considering the availability of these aspects if Elearning is to be deployed in remote areas where internet connection is not limited. These devices also run on electricity which is occasionally interrupted in some areas [31]. As students may come from a wide range of locations, educators should consider all potential issues when making decisions on whether an online program is possible to deliver.

\subsubsection{Students' Engagement}

To ensure learning results, it is the teachers' duty to keep students' attention away from distractions around them. Moreover, they also need to improve students' engagement in the lesson so that they are able to absorb the knowledge delivered. Only when teachers are able to do this can they create a successful E-learning learning experience [1]. 


\subsubsection{Computer Literacy}

In order to achieve high results in an online course, efforts are required from both teachers and learners in terms of technology literacy. As for students, most of the time, they are asked to explore a range of sites on the Internet for their assignments. This demands superb searching skills and computing ability for learning online [32].

On the other hand, it is vital for teachers to vary their teaching methodology in order to improve the teaching and learning process. They need to find ways to overcome all barriers of distance learning, such as lack of interaction and delayed feedback [24]. Consequently, teachers are compelled to improve their technical competence to accomplish their duty.

\subsubsection{Teachers' Adaptation}

Frequently, an online course originates from an existing offline one. Despite keeping similar learning outcomes, the design of the course should be rebuilt to adapt to the new approach. It is challenging for teachers to decide what to deliver to students beforehand and what activities to be used in virtual classrooms. This is especially difficult for educators who are new to this method of teaching [27].

\subsubsection{Educational Quality Assurance}

When teaching in online mode, it is challenging for educators to ensure a high standard of quality. Due to the lack of face-to-face interaction and instant feedback as aforementioned, learners may find themselves lost on the way to achieving their learning outcomes. Besides, those who are new to this approach, they are probably reluctant to express their thoughts, which leads to a reduction in the effectiveness of their learning. In terms of measurements, students are able to cheat easily in exams when these tests are conducted through the Internet. They can also copy from each other or from the Internet to complete their tests [23]. Therefore, controlling and preventing these disadvantages have been problematic for educators since the beginning of distance learning.

\subsection{Theoretical Concepts of E-Learning}

[33] discussed that people achieve critical thinking skills when they have interpersonal interaction within a community. We are frequently affected by our peers when we interact with each other. By doing so, we negotiate the meaning of the world and thus acquire knowledge. As was described by [35], the ability to think critically and creatively was defined at the higher level of the cognitive process. As a result, learning objectives in universities are regularly set at similar standards so that students are able to acquire a high degree of cognition. When planning online learning, it is the responsibility of educators to take these factors into consideration and assure that learners are expected to achieve after the learning process. To achieve this goal, it is crucial to define a framework that best describes the most important aspects of a learning experience.

[27] defined a framework called communities of inquiry comprising three factors namely social, cognitive and teaching presence (Figure 1).

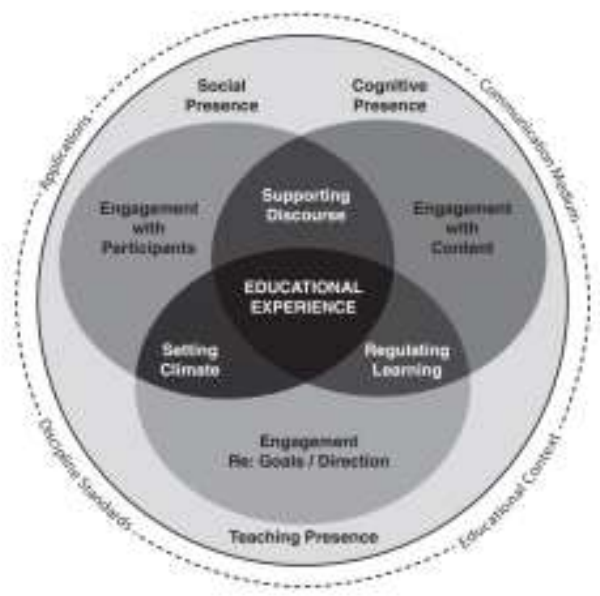

Figure 1 Community of Inquiry

\subsubsection{Social Presence}

This reveals the idea that participants of the course are able to group together in a truthful way so as to develop the bond of the community. This helps increase their knowledge by interacting with each other collaboratively. In order to achieve the best quality of a learning experience, it is crucial for teachers to be aware that students' participation itself is not adequate. There needs to be a solution to engage students, keep their focus, give and receive feedback on students' work and assess them appropriately [19]. To fulfill this mission, educators are obliged to make use of a learning management system to help foster their teaching process outside their traditional settings. [21] did research on using Moodle and found that there was a significant connection between students' autonomy and the learning environment deployed by teachers. 


\subsubsection{Cognitive Presence}

This is learners' ability to construct their awareness through activities that require judgment and meaning negotiation. To improve learners' satisfaction yet maintain a high standard of cognition, teachers also need to employ a range of strategies from organizing classroom discussions to making games online to facilitate learners' motivation. In a study by [22], the authors investigated the effectiveness of using games such as Kahoot or Quizizz for teaching university students. Results of the study showed that the uses of these games contributed to the increase of students' engagement in class when $100 \%$ of participants agreed on the deployment of gaming activities as an alternative approach for the learning experience.

\subsubsection{Teaching Presence}

This aspect is believed to be the most important element of the whole framework as it combines and balances all components together. The presence of not only a teacher but also all stakeholders leads the whole teaching and learning process towards the expected goals. Besides, rules to prevent the spread of the Covid-19 pandemic have continuously put all universities in lockdown mode. This fosters teachers and educators to find an alternative way to deliver their lessons while maintaining traditional values. One possible solution for this is organizing video meetings to connect teachers and learners from distances [20]. An example of this is a program named Zoom, which enables teachers to conduct online meetings, conferences, video discussions, and other uses [19].

\subsection{Challenges and Opportunities of E- Learning Employment at Tertiary Institutions}

With a comprehensive understanding of this research subject, a brief review of empirical studies was sought in both foreign and Vietnamese backgrounds.

[9] implemented a case study to examine the key challenges to the use of e-Learning at public Iraq universities. The authors utilized instruments such as surveys, semi-structured interviews, and focus groups with the involvement of academic staff, lecturers, and undergraduates. Having analyzed the data, they concluded that the hindrance of e-Learning is sorted into internal and external factors. To be specific, the drawbacks of e-Learning come from outside elements such as Internet access, the inadequacy of technical assistance, lack of training, poor ICT structure, etc., and inside elements such as computing literacy, motivation, and interest. It can be inferred that this study placed a focus on external problems. Meanwhile, in the current study, the significance of both factors was equally considered.

Adopting a different research method named survey, [10], [6], [7], and [11] reported that virtual learning had brought both benefits and drawbacks to students and teachers. The difference among the four studies is in the first one, merely teachers got involved while the second had the participation of only students and the rest engaged both teachers and students. The findings are also diversified among these empirical studies. The second showed that eLearning was beneficial to students in terms of learning autonomy but also caused certain troubles such as shortage of computers and Internet facilities and lack of access to e-Learning tools and facilities. Besides, the results of the third study were distinctively categorized into four dimensions: obstacles to implementing e-Learning, disadvantages of e-Learning, advantages of e-Learning, and the extent of using e-Learning. Meanwhile, the first study's findings are concerned with benefits and challenges encountered by teachers, and the second study's findings predominantly focus on specific challenges and point out that students have awareness and a positive attitude toward e-Learning convenience. Similarly, [12] employed a quantitative method to ponder the benefits and drawbacks of eLearning implementation from students' perceptions and found that disadvantages outweigh advantages. The students had a preference for traditional teaching methods in which motivation and interaction are tremendously enhanced. In short, the first study's objectives are the most similar to those of our study.

With mixed methods research design, [13] aimed to investigate the effectiveness of Blackboard- one of the e-Learning platforms from teachers' perspective. Having collected survey and interview data, the authors concluded that e-Learning has both advantages and disadvantages. The plus points are a stress-free environment, flexibility, and interaction outside class, whereas the minus points are lack of active participation, diminished motivation, and poor computing and writing skills.

In Vietnam, there have been a few studies undertaken to examine to what extent e-Learning is beneficial and challenging. [14] executed case study research to grasp the understanding of e-Learning adoption in Vietnamese tertiary institutions. The 
findings are quite broad and drawn from two kinds of perspectives: factor and implementation process. The former is related to "managerial setting, capacity and working environment; IT governance; academic changes and challenges; ICT strategy and capacity; ICT policy and management; and teaching and learning methods." The latter includes "resources and scope; the learning management system; involvement and commitment; motivation of adoption; operation and management; budget allocation \& investment; technological problems; attitudes and behavior; and challenges and future direction. It seems that the findings are quite general since they failed to specify the issue from each perspective.

Recently, under the context of Covid-19 emergence, [3] and [8] employed distinctive research methods with different objectives. The former had desk research to review the conveniences and obstacles of virtual learning and found that this kind of teaching was justifiable compared to emergency remote teaching. As for the latter, a virtual survey was administered to learn about students' satisfaction level with online learning. The findings revealed that the main troubles hindering e-Learning implementation are poor Internet access, disrupted connection, and low-quality sound. Moreover, the level of satisfaction when learning face-to-face is higher than learning virtually, and the lowest satisfaction degree is relevant to practice and studentstudent interaction. Overall, both mentioned studies show that online learning is modestly favored by students, and there are certain technical problems that prevent online learning efficiency.

\subsection{Research Gap}

After the previous studies have been generally reviewed, it is noticed that the overseas studies majorly had the investigation of either challenges or benefits and drawbacks of e-learning implementation. They employed two types of research methods, including case study and survey, and did not have many mixed-method types of research. [13] conducted a mixed-method (quantitative and qualitative) but focussed on Blackboard e-Learning platform while our study aims at three types: eLearning platforms, virtual classroom applications, and supporting teaching tools. Regarding the participants, most of them engaged only teachers, while a few appealed to both lecturers and students. The present study is a mixture of quantitative and qualitative methods with an aim to probe both challenges and opportunities of conducting virtual teaching from teachers' perspectives. One more thing is the findings of the previous studies did not specify which online teaching platforms, applications, and tools; their specific benefits and drawbacks. Hence, our study with the results of these points will be a significant contribution.

In the Vietnamese context, there were two main studies with objectives of investigating the positive and negative sides of e-Learning adoption as well as students' satisfaction from e-Learning, utilizing desk research and survey method, respectively.

Hence, the mixed-method study was conducted with the utilization of surveys and semi-structured interviews to not only dig into university lecturers' perspectives on challenges and opportunities when teaching virtually quantitatively but gain their indepth thoughts and practical experiences.

\section{METHODOLOGY}

Table 1. Participants' proficiency in using LMS, virtual classroom applications, and supporting tools for teaching

\begin{tabular}{|l|l|l|l|l|l|l|}
\hline Items/ Percentage & $\begin{array}{l}\text { Least } \\
\text { proficient }\end{array}$ & $\begin{array}{l}\text { A bit } \\
\text { proficient }\end{array}$ & $\begin{array}{l}\text { Quite } \\
\text { proficient }\end{array}$ & Proficient & $\begin{array}{l}\text { Very } \\
\text { proficient }\end{array}$ & $\begin{array}{l}\text { Most } \\
\text { proficient }\end{array}$ \\
\hline $\begin{array}{l}\text { E-learning } \\
\text { platforms }\end{array}$ & 1.4 & 2.9 & 11.6 & 20.3 & 52.2 & 11.6 \\
\hline $\begin{array}{l}\text { Virtual classroom } \\
\text { applications }\end{array}$ & 0 & 2.9 & 7.2 & 15.9 & 55.1 & 18.8 \\
\hline $\begin{array}{l}\text { Supporting } \\
\text { teaching tools }\end{array}$ & 0 & 4.3 & 8.7 & 24.6 & 47.8 & 14.5 \\
\hline
\end{tabular}




\subsection{Participants}

The research was implemented with the active engagement of 69 lecturers of English at Ho Chi Minh-based universities. Initially, the researchers expected the participation of 100 lecturers, but due to the Covid-19 pandemic, the sample size is restricted to this number. The female participants dominated the sample group with $71 \%$, followed by males and others (with 27.5 and $1.4 \%$, respectively). Most of them teach English-major students with $76.8 \%$, and the rest teach non-English major ones. They have diverse educational backgrounds, teaching experience, and computing literacy. Additionally, they are working in both state and private institutions.

With regard to proficiency in using e-Learning platforms, virtual teaching applications and supporting teaching tools, the following charts are presented.

As can be seen from Table 1, in all the three charts, the majority of participating lecturers are very and most proficient in applying e-Learning platforms, applications, and tools in English teaching, with $63.8 \%, 73.9 \%$, and $62.3 \%$, respectively.

\subsection{Research Design}

Both quantitative and qualitative methods were employed to finalize this small-scale research. The survey was virtually administered in order to examine the perceptions of university lecturers as a whole. Meanwhile, semi-structured interviews were conducted with three selected participants to dig into the in-depth thoughts and opinions on the implementation of e-Learning in teaching English. The mixed methods research facilitates gaining greater insights and providing an expanded understanding of the problem [15].

\subsection{Instruments and Sampling}

\subsubsection{Questionnaires}

Two major research instruments were exploited, including questionnaires and interviews. The survey was allocated to the lecturers, and 69 responses were recorded. Both random and non-random sampling was utilized to yield sufficient responses. The survey had 35 question items and consisted of four main sections: demographic information, Experience in using e-Learning platforms, Benefits of conducting eLearning in teaching English, and Problems when conducting E-learning. Specifically, questions 1 and 2 collect details about respondents' gender and the types of students they are in charge. Questions 3-4 (close-ended and scale type) deal with the types of eLearning Learning Management System (LMS), virtual classroom applications, and supporting teaching tools and proficiency scale of using these types. Notably, the question items 5-31 were designed in Likert scale 6-point form (totally disagree-disagree-a little disagree-a little agree-agreetotally agree) to obtain data about benefits of eLearning implementation in terms of interaction, students' learning, teaching process and motivation; and drawbacks of e-Learning platforms regarding interaction, computing literacy, teaching process, and technostress. Finally, questions 32 and 33 are sought to gather information about students' and teachers' difficulties in using e-Learning tools. Question 34 was given to learn about the respondents' willingness to conduct e-Learning.

Table 2. Reliability statistics

\begin{tabular}{|c|c|}
\hline $\begin{array}{l}\text { Cronbach's } \\
\text { Alpha }\end{array}$ & $\mathrm{N}$ of Items \\
\hline .869 & 26 \\
\hline
\end{tabular}

The reliability of the questionnaires is shown in Cronbach Alpha index as shown in Table 2. From the figure, we can see that the Alpha index is 0.87 (>.7), meaning that the internal reliability of the questionnaires ranked good, as what was discussed in [16]. Moreover, some items in the questionnaires were adapted from [13], which added more value to its reliability.

\subsubsection{Virtual Semi-Structured Interviews}


With the purpose of seeking the substantial sharing of

Finally, three participants were selected for

Table 3. Uses of e-Learning platforms, virtual classroom tools, supporting applications for teaching

$\begin{array}{lllllll}\text { Items } & \text { Moodle } & \begin{array}{l}\text { Google } \\ \text { classroom }\end{array} & \text { LMS } & \begin{array}{l}\text { Microsoft } \\ \text { teams }\end{array} & \text { Canvas } \\ \text { Percentage } & 33.3 \% & 60.9 & 7.2 & 39.1 & 10.1 \\ \text { Items } & \text { Zoom } & \text { Google meet } & \begin{array}{l}\text { Microsoft } \\ \text { teams } 1\end{array} & \text { Skype } & \text { Cisco Webex } & \text { Zalo } \\ \text { Percentage } & 60.9 & 76.8 & 34.8 & 4.3 & 1.4 & 1.4 \\ \text { Items } & \text { Mentimeter } & \text { Kahoot } & \text { Quizizz } & \text { Padlet } & \text { Quizlet } & \text { Flipgrid } \\ \text { Percentage } & 14.5 & 63.8 & 58 & 34.8 & 55.1 & 15.9 \\ \text { Items } & \text { Bamboozle } & \text { Nearpod } & \text { Classes } & \text { Facebook } & \text { Poll Everywhere } & \end{array}$

perceptions and experience in online teaching, three participants were selected for interviews with support of convenience sampling. To be specific, the interviewees were chosen based on the survey responses (totally agree, totally disagree, and a little agree) and the intimate relationship with the authors. The interviewees are designated as $\mathrm{F}$ (female) M1 (male 1), and M2 (male 2). The interview questions were in alignment with the constructs of the questionnaire, such as types of LMS, virtual applications, supporting teaching tools; their advantages and disadvantages; benefits, and difficulties when teaching online. Additionally, the authors desired to know about virtual teaching experience and suggestions to improve it.

\subsection{Data Collection Procedure}

In the first stage, pilot testing was conducted to check the validity of quantitative data. Specifically, the authors had an intention to check participants' comprehension of question items, the framework of the questionnaire, mechanics and language styles, etc. The initial survey was purposefully sent to 15 lecturers of English in Ho Chi Minh City via Google form.

Subsequently, after receiving the feedback from the mentioned participants and consulting an English specialist, the survey was comprehensively amended by omitting some troublesome items and adding some more items to collect sufficient data. Subsequently, the two authors officially sent the revised survey to friends and colleagues, as well as acquaintances via Facebook, Messenger, and Zalo (a popular social media tool in Vietnam). detailed interviews. Each of them was separately interviewed via Google Meet. All the talks were recorded for later analysis.

\section{FINDINGS AND DISCUSSION}

\subsection{Experience in Using E-Learning Platforms}

\subsubsection{Types of E-Learning Platforms, Virtual Teaching Application, and Supporting Teaching Tools}

From what can be seen in Table 3, the utilization of e-Learning platforms, virtual teaching sites, and teaching tools. It is apparent that in terms of an eLearning platform, Google classroom, Microsoft teams, and Moodle are the most preferred with $60.9 \%, 39.1 \%$, and $33.3 \%$, respectively, and followed by LMS and Canvas (7.2\% and 10.1\%). These findings are quite similar to interviewees' responses that two of them (F and M1) frequently use Moodle, Microsoft teams, and sometimes Canvas for training projects and the other tap into Moodle (M2).

As for virtual teaching sites, the table data clearly shows that most respondents choose Google to meet and Zoom (76,8\% and 60.9\%) in English teaching. The less preferred virtual teaching applications belong to Microsoft Teams, Skype, Cisco Webex, and Zalo. The interviewees asserted that Google meet and Zoom are dominantly used since they are userfriendly and cost-effective. It is noted that Microsoft teams accounted for the modest proportion (34.8\%). It can be interpreted that some of the lecturers are hesitant to use this application. One of the 
interviewees voiced her opinion on this tool. She showed her unwillingness to use Microsoft Teams since it is quite complicated in terms of registration and multifunction.

-"Microsoft teams have so many functions, and I have difficulty using it. My students also encounter this problem" $(\mathrm{F})$

By contrast, one male lecturer showed a positive attitude toward Microsoft teams. He prioritized this tool because of increased interaction between the teacher and students.

-"MS teams can give me many things. Like I can give them some pictures. I can share. It is similar to using Messenger. I can chat, give pictures, and share emoticons. Show emotions there. Lovely!” (M2)

Turning to ancillary teaching tools, Kahoot is the most used tool, making up 63.8\%. Quizizz and Quizlet shared the approximately same proportion with over $50 \%$, while the percentage of participants using Padlet nearly doubled that of Flipgrid, Mentimeter, and Nearpod. A negligible number of them adopted Baamboozle, Classes, Facebook and Poll Everywhere during their teaching process, with a similarity of $1.4 \%$. Two interviewees advocated Kahoot and Quizizz for student engagement, and the other did not use interactive tools due to time constraints and tight working schedules. One male interviewee mentioned the usage of those tools. He used various kinds of tools with distinctive purposes.

"I don't rely on one tool. I put them into different categories. If I want to prepare lessons, I use these tools. To increase engagement, I use Kahoot, Quizizz, Mentimeter, and Padlet" (M1).

The other male interviewee claimed that these tools help increase students' motivation and reduce stress after listening to a long lecture.

\subsubsection{Discussion}

As expected, it can be briefly reported that Google Classroom, Moodle, Google Meet, Zoom, Ms Teams, Kahoot, Quizizz, Quizlet are the e-Learning platforms, applications, and tools greatly favored by the lecturers. These findings are different from other previous studies. They only mentioned the positive and negative sides of E-learning in general but did not specify any types. Moreover, our findings reveal different forms of e-Learning while [13] only investigated the effects of Blackboard and [18] researched Google Classroom and Google Meet. It is one of the significant findings of this study.
In fact, during the Covid-19 outbreak, most universities in Ho Chi Minh City switched to the eLearning method, and the three main types of eLearning platform are used thanks to their convenience in learning management such as creating learning materials, opening virtual classes, administering tests, marking assignments, and discussion. It can be observed that many universities in HCMC have a preference for Google meet and Zoom thanks to user-friendliness. Compared to Microsoft teams, account registration for them is quite easy and time-saving. Despite its inconvenience, Microsoft teams- a so-called small LMS is selected by a small number of lecturers since it facilitates not only virtual teaching employment but other activities such as document uploading, discussion thread, assignment, notebook, etc. Skype and Zalo are not preferred because of unstable servers and unsuitability for big classes of more than 50 students.

To my knowledge, Kahoot and Quizzes are favorable interactive tools in engaging students in quizzes and games. Teachers give students a code, and students just click on it and respond to questions. Quizlet is an application for vocabulary development and interaction as well. Some of them do not use Quizlet simply since they teach other complicated modules rather than vocabulary.

\subsection{Benefits of E-Learning Adoption}

\subsubsection{Findings of E-Learning Benefits}

From Table 4, we can see that reduction in travel time, homework submission, and learning flexibility were three prominent upsides of e-Learning $(\mathrm{M}=4.97$, $\mathrm{M}=4.84, \mathrm{M}=4.70$ ).

In detail, it is clear from the data that question 12 "E-learning reduces the time to travel for teachers," had the highest mean score $(\mathrm{M}=4.97, \mathrm{SD}=1.2)$, which indicates that respondents show their agreement. Two interviewees affirmed themselves:

"One benefit of e-Learning is that I don't have to travel to school and save transportation costs" $(\mathrm{F})$.

"Students don't have to go out, so they can save time and money" (M2)

The three remaining question items shared a nearly similar figure and ranged from 4.12 to 4.3 . It can be inferred that there was a bit of agreement with the positive sides of e-Learning in preparing lessons, marking assignments, and considering individual learners among the participating lecturers. 
Regarding interaction, it is explicitly observed that questions 5,7,8 had mean scores of 3.88, 3.76, and 3.62 , respectively. It means that the lecturers somewhat agree that e-Learning helps students respond to questions excitingly, interact with each other via discussion threads, and interact with teachers. On the other hand, they slightly disagree that students interact effectively in e-Learning classes $(\mathrm{M}=3.46, \mathrm{SD}=1.31)$. The interviewees also slightly show disfavor of this statement as e-Learning caused a shortage of real interpersonal interactions between teachers and students.

"I lack interaction.... It's long time I haven't interacted directly with students because we cannot see our students because of lots of problems. Students may say I don't have time. I don't use my computer. Sometimes they lack a Wi-Fi connection. Just a few students are willing to turn on the webcam and connect" (M2)

Differing from the data in previous sections, all the respondents show their concurrence of the benefit of e-learning toward students in terms of material accessibility, homework submission, self-paced learning, and flexibility $(\mathrm{M}=4.52,4.84,4.58$, and 4.70 respectively). With regard to this point, the female Lecturer voiced her opinion on the flexibility and accessibility of e-Learning.

"Thanks to the e-Learning system, students can review the lessons after the class or when they are absent. Really flexible". They can access various kinds of materials.
Being similar to the results of the teaching process, the English lecturers showed both a bit of approval and approval of teachers 'motivation benefited from e-Learning. Specifically, the question related to the desire to learn about technology obtained the highest mean score of 4.49 and was followed by the question related to satisfaction with students' learning results $(\mathrm{M}=3.87)$ and fascination with online teaching $(\mathrm{M}=3.67)$. One of the interviewees shared something about it as well. Thanks to e-Learning, he had more motivation in exploring tools in English teaching.

"During the Covid-19 period, I learned to use different tools. To teach online effectively, I have to familiarize myself with tools about creating materials, engaging students, and administering tests" (M1).

\subsubsection{Discussion}

Briefly, the participants show their agreement with the convenience of e-Learning to a certain extent except for in-class interaction (a bit of disagreement). As expected, the findings are quite in line with [28], [13], [6], and [19]. Some stunning beneficial factors in the current study's findings match those in previous studies include interaction, accessibility, flexibility, self-paced learning, homework submission, and marking homework. The rest, such as individual learner, reduction in traveling time, 
amusement in online teaching, promotion in the desire to learn about technology, and satisfaction with learners' results, are emerging findings based on our teaching experience and not found in previous studies. Noticeably, we classified different types and times of interaction: in class, between teachers and students outside class, peer interaction on the forum. We assume that e-Learning may have different effects on these types and times of interaction.

As for the results indicating that the participants show somewhat disagreement, they can be interpreted from our practical teaching. From my teaching experience, I had great trouble interacting with my students during the virtual teaching period. There are some underlying causes such as poor

Table 5. Responses about the drawbacks of e-Learning

\section{Items}

20. Isolated when teaching

21. Communication skills are not developed

22. Students do not participate actively

23. Teachers' not good computing skills

24. Learn tools slowly

25. Require more teachers' effort

26. Percentage of students finishing homework is low

27. Students copy homework from each other

28. Not think online learning is effective

29. Feel stressed teaching online

30. Tired of looking at the screen

Internet connection, defective cameras, power shortage, or students' distraction. Sometimes I called them, but just a few responded. However, when I used some kinds of interactive tools, they participated quite eagerly. It means that e-Learning is not totally troubling in increasing students' interaction during the lecture delivery.

"I don't see them in person. I'm afraid that some kinds of nonverbal communication such as gestures, posture, eye contact cannot be used" (M2)

\subsection{Drawbacks of E-Learning}

As illustrated in Table 5, three main downsides of e-Learning include teachers' increased effort, students' cheating behavior and teachers' physical tiredness $(\mathrm{M}=4.91, \mathrm{M}=4.29, \mathrm{M}=4.14)$.

To be specific, questions 20 and 21 had mean scores of 3.45 and 3.1, indicating that the participants slightly disagree that teachers suffer from isolation and worsened communication skills when teaching virtually. Being consistent with the results of eLearning benefits in students' participation (a bit disagree), they showed a bit of agreement with question 22. One female interviewee said:

"I feel lonely when teaching online. Just talk in

$\begin{array}{lll}\mathbf{N} & \text { Mean } & \text { SD } \\ 69 & 3.45 & 1.290 \\ 69 & 3.10 & 1.285 \\ 69 & 3.70 & 1.407 \\ 69 & 2.33 & 1.146 \\ 69 & 2.43 & 1.206 \\ 69 & 4.91 & 1.095 \\ 69 & 3.46 & 1.267 \\ 69 & 4.14 & 1.407 \\ 69 & 3.23 & 1.285 \\ 69 & 3.26 & 1.313 \\ 69 & 4.29 & 1.273\end{array}$

front of the computer" (F)

One male interviewee showed his worry that communication might be reduced 
It is interesting to note that the lecturers showed their disapproval of the statement "I do not have good

\subsubsection{Difficulties of Both Lecturers and}

Table 6. Responses about difficulties when teaching online

\begin{tabular}{|l|l|l|l|l|l|l|l|}
\hline Item & $\begin{array}{l}\text { Poor } \\
\text { internet } \\
\text { connection }\end{array}$ & $\begin{array}{l}\text { Unexpected } \\
\text { interruption }\end{array}$ & $\begin{array}{l}\text { Power } \\
\text { shortage }\end{array}$ & $\begin{array}{l}\text { Poor } \\
\text { computing } \\
\text { skills }\end{array}$ & $\begin{array}{l}\text { Learning } \\
\text { autonomy }\end{array}$ & $\begin{array}{l}\text { Short } \\
\text { attention } \\
\text { span }\end{array}$ & Noise \\
\hline Percentage & 88.4 & 73.9 & 39.1 & 44.9 & 1.4 & 1.4 & 1.4 \\
\hline Item & $\begin{array}{l}\text { Create } \\
\text { virtual } \\
\text { classroom }\end{array}$ & $\begin{array}{l}\text { Create } \\
\text { teaching } \\
\text { materials }\end{array}$ & Share audio & Control class & & & \\
\hline Percentage & 20.3 & 34.8 & 33.3 & 71 & & &
\end{tabular}

computing skills to teach online"; "I learn to use online tools very slowly" (M=2.33, $\mathrm{M}=2.43)$.

Table 6 shows the fact that two major obstacles students confronted in e-Learning classes were poor Internet connection and unexpected interruption, with 88.4 and $73.9 \%$, respectively. The next groups of problematic issues were power shortage and poor computing skills with quite similar percentages. The smallest proportion of respondents' vote belonged to learning autonomy, short attention span, and noise with $1.4 \%$ alike.

Meanwhile, class management had the highest figure, constituting nearly three quarters. It can be implied that the biggest trouble the lecturers encountered was the method of supervising students. The interviewees also had the same opinion on this issue.

"The most trouble I have is controlling students. Because some of them don't turn on their cameras and I can't see them. I don't know what they are doing and whether they are concentrating on studying or not. Or maybe they lose Internet connection so I can't talk to them" (F)

\subsubsection{Discussion}

It is reported that teachers totally agree and agree that e-Learning causes a great effort of teachers, physical exhaustion and increased students' misbehavior, and three main types of obstacles were Internet connectivity, unexpected interruption, and poor classroom management. These findings were somewhat in alignment with [10] and [6], who mentioned some kinds of troubles such as Internet connection, time and effort consumption, and no interest. One more interesting result of this study is the participants disagree that they have poor
Students When Teaching Online

computing skills and consume much time in learning about technology. These findings are for the authors' expectation for some reasons. A switch from oncampus learning to e-Learning takes lots of work, such as familiarising with e-Learning platforms, applications, and tools, conducting virtual lessons, handling lots of issues occurring. They have to look at the screen frequently, resulting in being tired and suffering some physical pains. When learning online, it is easier for students to cheat by copying from other sources, discussing with their peers, and so on. Finally, the enhancement in computing skills can be explained thanks to institutional support and some kinds of training which help teachers in conducting eLearning effectively.

\section{CONCLUSION}

In a nutshell, there is a likelihood that tertiary institutions will increasingly employ e-Learning. Elearning not only generates benefits but causes certain troubles to teachers and learners as well. The study with a combination of surveys and semistructured interviews showed that the substantial advantages of virtual learning involve reduced traveling time, assignment submission, and flexible learning. The modest advantages included self-paced learning, material accessibility, assignment rating, and lesson preparation. The least advantage belonged to on-campus interaction. Turning to the drawbacks and difficulties, an increase in teachers' effort, students' misbehavior, and teachers' physical tiredness and class management were the factors hindering e-Learning implementation. 
It is recommended that e-Learning should be applied in English teaching thanks to its convenience. Teachers can incorporate e-Learning into different teaching activities, from creating materials to marking students' papers. Besides, teachers should consider using tools that are user-friendly and timesaving to maximize their benefits and enhance the teaching practice. To enhance in-class interaction and class management, teachers are advised to adopt a variety of strategies and teaching tools to boost their engagement. Finally, institutions can provide the necessary support to help teachers reduce stress.

There are some limitations to this study. Due to the limited participants, the data are somehow insufficient. In addition, online administered surveys cause troubles in collecting a large number of responses as expected. Finally, time constraints prevent the authors from implementing more interviews.

\section{AUTHOR'S CONTRIBUTION}

The group of researchers as authors of the paper designed and collected data from September-October 2021. We hereby confirm that all findings and discussion were based on our own work, without any use of other sources except for relevant ideas from literature as cited.

\section{ACKNOWLEDGMENTS}

We would like to express our gratitude to all lecturers who participated in the surveys and interviews. They are a great help in our study completion.

\section{REFERENCES}

[1] M. Samir, Abou El-Seoud, A.T.F. Islam, TajEddin, Naglaa Seddiek, E-Learning and Students' Motivation: A Research Study on the Effect of E-Learning on Higher Education, International Association of Online Engineering, 9 (4) (2014)

[2] K. N. N. Tran, The Adoption of Blended ELearning Technology in Vietnam Using a Revision of the Technology Acceptance Model, Journal of Information Technology Education: Research, 15 (2016), p253-282

[3] Dinh, L. P., \& Nguyen, T. T, Pandemic, social distancing, and social work education: Students' satisfaction with online education in Vietnam, Social Work Education, 39(8) (2020), 10741083.
[4] H. Aldowah, S. Ghazal, B. Muniandy, Issues and Challenges of using E-Learning in a Yemeni Public University, Indian Journal of Science and Technology, 8(32) (2015), DOI: $10.17485 / \mathrm{ijst} / 2015 / \mathrm{v} 8 \mathrm{i} 32 / 92160$

[5] E. K. Abed, Electronic Learning and its Benefits in Education. Eurasia Journal of Mathematics, Science and Technology Education, 15(3), 2019. DOI: https://doi.org/10.29333/ejmste/102668

[6] Hennig, S. and Nazarkulova, A., Benefits and Challenges of eLearning in Central Asia, International Journal of Geoinformatics, 15 (4), 2019

[7] Mohammed Mohammed Nasser Hassan Ja'ashan, The Challenges and Prospects of Using E-learning among EFL Students in Bisha University, Arab World English Journal (AWEJ) 1(1) (2020), pp.124-137 DOI: https://dx.doi.org/10.24093/awej/vol11no1.11

[8] Ho Nhut Quang, Ha Minh Tri, The challenges and opportunities of online learning during Covid-19 pandemic, HCMCOUJS-Social Sciences, 11(1) (2021), 3-14, DOI:10.46223/HCMCOUJS.

soci.en.11.1.1902.2021

[9] Ahmed Al-Azawei1, Patrick Parslow, Karsten Lundqvist, Barriers and Opportunities of ELearning Implementation in Iraq: A Case of Public Universities, International Review of Research in Open and Distributed Learning, 17 (5) (2016).

[10] Olukayode Solomon Aboderin, Challenges and Prospects of E-learning at the National Open University of Nigeria, Journal of Education and Learning, 9(3) (2015), pp. 207-216

[11] Maatuk, A.M., Elberkawi, E.K., Aljawarneh, S. et al. The COVID-19 pandemic and E-learning: challenges and opportunities from the perspective of students and instructors. J Comput High Educ (2021). DOI: https://doi.org/10.1007/s12528-021-09274-212.

[12] Jomana S. Zboun, Mohammed Farrah, students' perspectives of online language learning during corona pandemic: benefits and challenges, indonesian EFL journal (ieflj), 7 (1) (2021), pissn 2252-7427, e-issn 2541-3635

[13] Nalliveettil George Mathew, Pusuluri Sreehari, talah M Al-Rubaat, challenges and implications of virtual e-Learning platform in EFL context: 
perceptions of teachers, International Journal of English Language Teaching, 7 (2) (2019) pp.100-116

[14] Dang Cong Tuan, Implementing E-learning in Vietnamese Universities: A Configurational Approach, Doctoral dissertation (2014).

[15] John W. Creswell, Research design: Qualitative, Quantitative, and mixed methods approaches, Sage Publications (2009).

[16] Sagar K. Wadkar, Khajan Singh, Ritu Chakravarty, Shivaji D. Argade, Assessing the Reliability of Attitude Scale by Cronbach's Alpha, Journal of Global Communication, 9(2), (2016), DOI: http://dx.doi.org/10.5958/0976$\underline{2442.2016 .00019 .7}$

[17] Kamal Kant, Dr Shilpa Parihar, E-Learning: Opportunities \& Challenges for Learners of modern Era, Journal of Emerging Technologies And Innovative Research, 8(8) (2021),

[18] B. Xhaferi, G, Xhaferi, Online Learning Benefits and Challenges During the COVID 19 Pandemic-Students' Perspective from SEEU. SEEU Review,15(1), 2020, pp. 86-103. DOI: https://doi.org/10.2478/seeur-2020-0006

[19] S. Dhawan, Online Learning: A Panacea in the Time of COVID-19 Crisis. Journal of Educational Technology Systems, 49(1), 2020, pp. 5-22. DOI:10.1177/0047239520934018

[20] I. A. Qureshi, K. Ilyas, R. Yasmin, Challenges of implementing e-Learning in a Pakistani university. Knowledge Management \& ELearning: An International Journal, 4(3), 2012, 310-324.

[21].B. Bervell, V. Arkorful, LMS-enabled blended learning utilization in distance tertiary education: establishing the relationships among facilitating conditions, voluntariness of use and use behaviour. International Journal of Educational Technology in Higher Education, 17(6), 2020. doi:https://doi.org/10.1186/s41239020-0183-9

[22] R. A. Rahman, S. Ahmad, U. R. Hashim. The effectiveness of gamification technique for higher education students' engagement in polytechnic Muadzam Shah Pahang, Malaysia. nternational Journal of Educational Technology in Higher Education, 15(41), 2018. DOI :https://doi.org/10.1186/s41239-018-0123-0
[23] V. Arkorful, N. Abaidoo, The Role of eLearning, the Advantages and Disadvantages of Its Adoption in Higher Education. International Journal of Education and Research, 2(12), 2014, pp. 397-410.

[24] B. Brandon, The eLearning Guild's Handbook of e-Learning Strategy: The eLearning Guild, 2007

[25] D.M. Voronin, V.G. Saienko, H.V. Tolchieva, Digital Transformation of Pedagogical Education at the University (DETP 2020), Advances in Social Science, Education and Humanities Research, 2020 DOI: https://doi.org/10.2991/assehr.k.200509.135

[26] D. Elkins, D. Pinder, E-Learning fundamentals: A practical guide: Association for Talent Development (ATD), 2015.

[27] D. R. Garrison, E-Learning in the 21st Century: A Framework for Research and Practice, 2nd edition: Routledge, 2011.

[28] B. Gilbert, Online Learning Revealing the Benefits and Challenges: St. John Fisher College, 2015.

[29] B. Holmes, J. Gardner, E-Learning: Concepts and Practice. London: SAGE Publications Ltd, 2006.

[30] W. Horton, E-Learning by Design (2nd ed.). San Francisco, CA: Pfeiffer, 2012.

[31] L. Mishra, T. Gupta, A. Shree, Online teachinglearning in higher education during lockdown period of COVID-19 pandemic. International Journal of Educational Research Open, 1, 100012, 2020. DOI: https://doi.org/10.1016/j.ijedro.2020.100012

[32] M. Radović-Marković, Advantages and Disadvantages of E-Learning in Comparison to Traditional Forms of Learning. Annals of the University of Petrosani, Economics, University of Petrosani, Romania, 10(2), 2010, pp. 289-298.

[33] L. S. Vygotsky, Mind in Society: Development of Higher Psychological Processes: Harvard University Press, 1978.

[34] P. Vo, An investigation of ICT policy implementation in an EFL teacher education program in Vietnam. https://ro.ecu.edu.au/theses/2250, 2019

[35] L.W. Anderson, D. R. Krathwohl, A Taxonomy for learning, teaching, and assessing: A revision of Bloom's Taxonomy of educational objectives. New York: Longman, 2001. 